\title{
Effects of Intermittent or Continuous Training on Speed, Jump and Repeated-Sprint Ability in Semi-Professional Soccer Players
}

\author{
M. Aguiar ${ }^{1}$, C. Abrantes*,1, V. Maçãs ${ }^{1}$, N. Leite ${ }^{1}$, J. Sampaio $^{1}$ and S. Ibáñez ${ }^{2}$ \\ ${ }^{I}$ Department of Sport Sciences, University of Trás-os-Montes e Alto Douro, Vila Real, Portugal and ${ }^{2}$ Faculty of Sport \\ Sciences, University of Extremadura, Cáceres, Spain
}

\begin{abstract}
The purpose of this study was to compare the effect of two different training interventions (Intermittent versus Continuous training) on semi-professional male soccer player's speed, jump and repeated-sprint ability. Thirty four players were divided into an intermittent training group (INT, $\mathrm{n}=18$, age $=26.7 \pm 4.7$, height $=175.3 \pm 5.2 \mathrm{~cm}$, weight $=72.9 \pm 4.8 \mathrm{Kg}$ ) and a continuous training group (CONT, $\mathrm{n}=16$, age $=26.6 \pm 5.1$, height $=174.9 \pm 5.9 \mathrm{~cm}$, weight $=73.2 \pm 7.2 \mathrm{Kg}$ ). The study lasted for 12 weeks and consisted of 20 minutes per training session in physical conditioning following either CONT or INT training guidelines. The players were tested 3 times during 1st, 6th and 12th week of the season. Testing consisted of $15 \mathrm{~m}$ and $30 \mathrm{~m}$ sprint time, squat-jump and countermovement jump height and Bangsbo modified sprint test. Two-way repeated measures ANCOVA (group: INT, CONT x TIME-POINT: Week1, Week6, Week12) showed that INT was faster than CONT in the $6^{\text {th }}$ and $12^{\text {th }}$ weeks for the squat jump, $15 \mathrm{~m}, 30 \mathrm{~m}$ and Bangsbo Modified Sprint Test and that INT recovered better from intense efforts than CONT. Our results suggest that both training interventions were able to maintain initial values of speed and jump. However, the INT exhibit larger improvements in repeated-sprint ability. Therefore, the power endurance training (intermittent high intensity exercise) may be more beneficial to prepare soccer players according to the game cardiovascular and metabolic specific determinants.
\end{abstract}

\section{INTRODUCTION}

Success in soccer requires high-level technical, tactical and physical skills. Available research on soccer performance has often focused on technique and tactics at the expense of physical resources such as endurance, strength and speed [1]. When played at the elite level, soccer requires endurance, speed, agility and power. The rate of work of a soccer player ranges between low-level activities like walking, jogging and those of high-intensity like sprinting. Research in this area has consistently focused on creating new techniques for enhancing soccer player's performance. These techniques have led investigators to create soccer-specific exercise testing protocols by extensively analysing match play at the elite level [2]. Studies have been conduced to monitor power endurance activity such as overall distance covered, average intensities, and percentage of time spent walking, jogging, running and sprinting during match play [2-4]. Studies results characterize soccer as a team sport based in explosive actions such as kicking, jumping and sprinting [5]. Furthermore, fitness improvements specific to this activity pattern have been defined as power endurance [6].

These studies of movement patterns have provided researches with the scientific basis for developing not only soccer-specific exercise testing procedures, but also applicable conditioning and training protocols $[7,8]$. The conditioning programs are based on the specific physiological demands of the elite game, and have been built to focus on the

*Address correspondence to this author at the Department of Sports Sciences, University of Trás-os-Montes e Alto Douro, Vila Real, Portugal; E-mail: abrantes@utad.pt high-intensity, intermittent aspects of fitness [9, 10]. Commonly used exercises include plyometrics, resistive training and various forms of intermittent training $[10,11]$. The effect of incorporating soccer-specific training into fitness protocols and assessment procedures has been well documented at the elite level [4, 8-11]. However, this focus on elite level players creates difficulties when interpreting training protocols and testing procedures for coaches competing in lower competition levels. In fact, research on semi-professional players is less common and training protocols have to be modified to more closely simulate "nonelite" match requirements.

The literature reveals that soccer players running speed can be improved following several types of training interventions such as sprint training, towing, overspeed [12], and specific plyometrics exercises [13]. The jumping ability depends on interlimb coordination, muscle type fibre and occasionally, on maximum strength, depending on the level of the player [14]. Vertical jump is improved through various types of training interventions, such as jumping exercises [14-16], depth jump, resistance training $[14,15]$ and combination of plyometric exercises and electroestimulation [17].

It has been demonstrated that explosive-type resistance training is more effective in improving vertical jump compared to high-resistance training [16]. However, it has also been reported that resistance training does not always result in enhancement of vertical jump, which is affected by other factors such as learning effect [18], training status [19] and volume training [20]. Other studies reported that combined training programs including resistance and explosive unloaded tasks such as throwing, jumping or kicking in the same training session may improve muscular strength and the speed of execution on the task [5, 12, 14, 21-23]. Long 
term changes in soccer players repeated sprint ability is not documented.

Another question that remains unknown in the literature is the structure of training models and their long term impact on soccer players' physical fitness. In fact, in order to meet the specificity principle of training, it seems that soccer training models should be based on competition physiological determinants and, soccer practices should prepare players to respond adequately to these requirements. Thus, the purpose of this investigation is to identify the effect of 12 weeks of intermittent aerobic versus continuous training interventions on speed and repeated-sprint ability in semiprofessional soccer players.

\section{METHODS}

\section{Subjects}

Thirty four Portuguese semi-professional soccer players were randomly assigned into two intervention groups: the intermittent (INT) training group and the continuous (CONT) training group (see Table 1). The groups were pair matched based on physical and performance data (i.e., they were not different from each other prior to commencing the specific training interventions). The players that didn't complete all the testing or training for any reason were removed from the sample.

Table 1. Characteristics of the Soccer Players (Mean \pm SD)

\begin{tabular}{|c|c|c|}
\hline & INT $(\mathbf{n = 1 8})$ & CONT $(\mathbf{n}=\mathbf{1 6})$ \\
\hline \hline Age & $26.67 \pm 4.69$ & $26.63 \pm 5.06$ \\
\hline Years of experience & $15.22 \pm 4.41$ & $13.88 \pm 5.07$ \\
\hline Height $(\mathrm{cm})$ & $175.33 \pm 5.18$ & $174.88 \pm 5.90$ \\
\hline Weight $(\mathrm{Kg})$ & $72.94 \pm 4.76$ & $73.19 \pm 7.22$ \\
\hline BMI $\left(W / H^{2}\right)$ & $23.73 \pm 1.28$ & $23.90 \pm 1.66$ \\
\hline
\end{tabular}

\section{Testing Procedures}

Testing occurred in the first, sixth and twelfth week of the competitive season. In the pre-season, both groups performed 5 weekly training sessions (each one lasting 120 minutes) and played one game. In the competitive season, they performed 4 training sessions (each one lasting 90 minutes) and played one game. During each training session, coaches spent 20 minutes to specific conditioning develop- ment according to each intervention guidelines. The groups were tested at the same hour of the day (19:00-21:00h), always after the weekly rest day. Before the tests, all players performed a standardized 25 minutes warm up, that consisted of jogging, sprinting, stretching, and tests familiarization.

\section{Intermittent Aerobic Training}

This training intervention was based on soccer external structure. The workload for the whole training sessions was the following: warm-up during $15 \mathrm{~min}$; intermittent aerobic training intervention during $20 \mathrm{~min}$ (see Table 2); small sided games during $40 \mathrm{~min}(3 \times 3,4 \times 4,5 \times 5,6 \times 6)$. This intervention was adapted from Balčiūnas et al. [24].

\section{Continuous Training}

This training intervention was based on time motion analysis data. The drills were planed and performed continuously using game like situations. The workload for training sessions was the following: warm up during $15 \mathrm{~min}$; continuous training intervention during $20 \mathrm{~min}$ (see Table 2); small sided games during $40 \mathrm{~min}(3 \times 3,4 \times 4,5 \times 5,6 \times 6)$. This intervention was adapted from Balčiūnas et al. [24].

\section{Speed}

Speed was evaluated by maximal $15 \mathrm{~m}$ and $30 \mathrm{~m}$ sprints, respecting the following protocol: players executed three maximal sprints with $15 \mathrm{~m}$ and $30 \mathrm{~m}$, with 3 minutes rest interval between each sprint. The players started to run $1 \mathrm{~m}$ before the photoelectric cells (Digest 1000, Digest Oy, Finland) and they only slowed $1 \mathrm{~m}$ after they passed by the second pair of cells. The best of the 3 obtained times was recorded for data analysis.

\section{Vertical Jump}

Vertical jumps were measured with both squat jump and countermovement jump protocols. The squat jump consisted of the subject performing a maximal vertical jump with their hands on the waist, starting from an angle of $90^{\circ}$ at the knee. The countermovement jump consisted of subjects performing a maximal vertical jump starting from a standing position with arm swing allowed. All jumps were performed on the Ergojump (Globus Inc., Italy) that recorded the flight time of all jumps. The flight time was used to calculate the change in the height of the body's centre of gravity [25]. Subjects performed three trials in each protocol and the best jump height was used in the analysis. Test reliability was high for both tests (respectively, SEM $=0.05 \%$ and $\mathrm{SEM}=0.04 \%$ ).

Table 2. Characteristics of the Training Programs

\begin{tabular}{|c|c|c|}
\hline & INT & CONT \\
\hline \hline Work-rest ratio (sec) & $15: 15,5: 25,10: 20,15: 30$ & $15: 15,20: 15$ \\
\hline Duration of the series (min) & 6 to 10 & 3 \\
\hline Number of series & 2 or 3 & 3 to 5 \\
\hline Recovery between series (min) & 6 to 10 & $65 \pm 5 \%$ \\
\hline Average intensity (\% maximal heart rate) & $80 \pm 15 \%$ & 3 \\
\hline
\end{tabular}




\section{Repeated-Sprint Ability}

The protocol consisted of seven maximal $34.2 \mathrm{~m}$ sprints $[3,4]$. Each sprint was performed with a change in direction (indicated by a light-emitting diode) as showed on Fig. 1. Photoelectric cells (Digitest 1000, Digitest Oy, Finland) were used to measure the subjects' performance and to increase test reliability. Following each sprint there was a period of active recovery ( $25 \mathrm{~s}$ to cover a distance of $40 \mathrm{~m}$ ), which consisted of jogging. Recovery was timed (stopwatch) in order to ensure that subjects returned to initial point of course between the 23rd and 24th second. Additionally, verbal feedback was given at $5,10,15$, and $20 \mathrm{~s}$ of the recovery. Performance was measured as the mean sprint time in seconds and fatigue index.

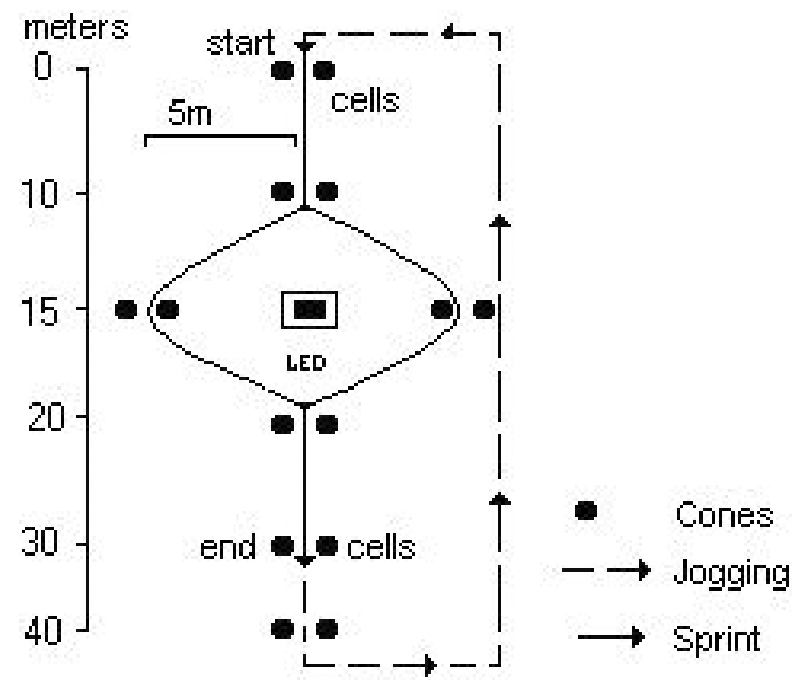

Fig. (1). Diagram of Bangsbo Modified Sprint Test protocol.

\section{Data Analysis}

A 3x2 repeated measures ANCOVA with Tukey's HSD was used to assess within group differences between time points $\left(1^{\text {st }}\right.$ week, $6^{\text {th }}$ week, $12^{\text {th }}$ week $)$ and between group differences (INT and CONT). When statistically significant differences were found, effect size (ES) was calculated according to Cohen [38]. All data undergoing ANCOVA were tested for assumptions of normality, homogeneity of variance and covariance matrices and sphericity. Neither assumption was violated. Statistical significance was set at $5 \%$.

\section{RESULTS}

The descriptive results ( $x \pm$ S.D.) and the statistically significance differences are found in Table 3. In general, results showed that INT was significantly faster than CONT $(15 \mathrm{~m}$ speed test and 30m speed test). The results from Bangsbo's Modified Sprint Test showed that INT was faster and recovered better from the intense efforts than CONT.

\section{DISCUSSION}

The purpose of this investigation was to study the changes in semi-professional soccer player's speed and repeated-sprint ability, when performing intermittent or continuous training programs. Such information would provide clear direction for coaches and players in the development of training programs.

The results observed on sprint tests in the current study confirm the results found on other populations in previous studies $[12,16,26-28]$. The CONT group did not show any significant improvement while there were significant improvements in the INT group in the sprint and jump tests. This suggests that the intermittent training intervention increased significantly the acceleration capacity and soccer

Table 3. Descriptive Results $(M e a n \pm S D)$ and Statistical Significant Differences

\begin{tabular}{|c|c|c|c|c|}
\hline Test & Time-Point Group & $1^{\text {st }}$ Week & $6^{\text {th }}$ Week & $12^{\text {th }}$ Week \\
\hline \multirow{2}{*}{15 m Speed* } & CONT & $2.30 \pm 0.08$ & $2.31 \pm 0.09 ¥$ & $2.30 \pm 0.09 ¥$ \\
\hline & INT & $2.19 \pm 0.08$ & $2.19 \pm 0.06$ & $2.16 \pm 0.05$ \\
\hline \multirow{2}{*}{30 m Speed* } & CONT & $4.23 \pm 0.25$ & $4.23 \pm 0.25 ¥$ & $4.20 \pm 0.26 ¥$ \\
\hline & INT & $4.02 \pm 0.11$ 末 & $4.03 \pm 0.15$ & $3.97 \pm 0.13$ \\
\hline \multirow{2}{*}{ Squat-jump* } & CONT & $39.9 \pm 1.3$ & $38.6 \pm 1.5 ¥$ & $39.1 \pm 1.4 ¥$ \\
\hline & INT & $42.0 \pm 1.3 \ddagger$ & $42.6 \pm 1.4$ & $44.1 \pm 1.3$ \\
\hline \multirow{2}{*}{ Counter-movement jump } & CONT & $38.3 \pm 1.3 \dagger t$ & $40.2 \pm 1.4$ & $40.1 \pm 1.1$ \\
\hline & INT & $39.3 \pm 1.2 \dagger \neq$ & $41.6 \pm 1.3$ & $43.6 \pm 1.0$ \\
\hline \multirow{2}{*}{ Bangsbo Modified Sprint Test* } & CONT & $7.31 \pm 0.34 \dagger \dagger$ & $7.19 \pm 0.35 ¥$ & $6.93 \pm 0.39 ¥$ \\
\hline & INT & $6.69 \pm 0.20 \dagger+$ & $6.39 \pm 0.19$ & $6.28 \pm 0.20$ \\
\hline Bangsbo Modified Sprint Test* & CONT & $0.48 \pm 0.09 \dagger \dagger$ & $0.44 \pm 0.08 ¥$ & $0.37 \pm 0.04 ¥$ \\
\hline (fatigue index) & INT & $0.34 \pm 0.08 \dagger+$ & $0.25 \pm 0.07$ & $0.18 \pm 0.04$ \\
\hline
\end{tabular}

$¥$ denotes statistical significant differences in GROUP; $\dagger$ vs. TIME POINT 6th; $\ddagger$ vs. TIME POINT 12 th; $*$ in GROUP $\times$ TIME POINT.

There was statistical significant differences between the groups in the $15 \mathrm{~m}$ Speed $(\mathrm{F}=4.05 \mathrm{p} \leq 0.05 \mathrm{ES}=0.13), 30 \mathrm{~m}$ Speed $(\mathrm{F}=5.15 \mathrm{p} \leq 0.01 \mathrm{ES}=0.25)$ and $\mathrm{Squat} \mathrm{Jump}(\mathrm{F}=4.50 \mathrm{p} \leq 0.05$ $\mathrm{ES}=0.35$ ). In Bangsbo Modified Sprint Test and fatigue index the differences between groups were also significant $(\mathrm{F}=6.47 \mathrm{p} \leq 0.01 \mathrm{ES}=0.36$ and $\mathrm{F}=8.97 \mathrm{p} \leq 0.01 \mathrm{ES}=0.37$, respectively). No significant differences were found in the Counter Movement Jump ( $F=1.40 \mathrm{p}=$ n.s.). 
players' maximum speed, being more efficient in the preparation of the players than the continuous training intervention. The improvements obtained by INT along the study could be the result of a combination of capacities (e.g. jump, sprint, tackle, direction changes, etc) worked with the application of the intermittent training intervention that according to the literature have an impact on strength and speed of tasks execution $[4,11,14,16,21-23]$. These improvements also can be attributed to neural adaptations and learning effects induced by the training [5].

The results of the Bangsbo Modified Sprint Test confirmed results obtained in the simple sprints tests. In these tests, INT was faster than CONT. This fact confirms the results available in the literature [3, 29- 33], which identifies a high positive correlation between the speed and the time of the first two sprints. Aziz et al. [33] and Abrantes et al. [3] suggested that these results also have a high positive correlation with the repeated-sprint ability. Our results confirm also the existent controversy in the literature [33-37] about the relative importance of the aerobic and anaerobic energy systems in performing repeated efforts. The INT group also maintain the capacity to recover between efforts. As suggested by Dowson et al. [30], our results show that the capacity to accomplish repeated efforts of high intensity has a weak dependence of the aerobic capacity, The CONT submitted to continuous training obtained weak improvements in the total average time and also on partial sprints. However, the improvements obtained by CONT did not have repercussions in recovery capacity between efforts as it was demonstrated by the increases of the times to accomplish the last sprints. It is in the recovery that some metabolic indicators of the aerobic preparation are clear in the repeated efforts [33, 34, 36], thus, the results obtained by INT, demonstrated that a training intervention based on the internal structure of the game, with great incidence in the repeatedsprint ability, has more impact in this capacity than a training intervention only based on continuous training.

\section{CONCLUSION}

Our results suggest that both training interventions were able to maintain initial values of speed and explosive strength. The intermittent training intervention may be more beneficial to prepare semi-professional soccer players according to the game cardiovascular and metabolic specific determinants.

\section{REFERENCES}

[1] Helgerud J, Engen C, Wisloff U et al. Aerobic Endurance Training Improves Soccer Performance. Med Sci Sports Exerc 2001; 33(11):1925-1931.

[2] Drust B, Reilly T, Cable N. Physiological responses to laboratorybased soccer-specific intermittent and continuous exercise. J Sports Sci 2000; 18(11): 885-892.

[3] Abrantes C, Maçãs V, Sampaio J. Variation in Football players' sprint test performance across different ages and levels of competition. J Sports Sci Med 2004; 3(YISI 1): 44-49.

[4] Bangsbo J. Physiology of soccer. Copenhagen, Storm 1994.

[5] Kotzamanidis C, Chatzopoulos D, Michailidis C et al. The effect of a combined high-intensity strength and speed training program on the running and jumping ability of soccer players. J Strength Cond Res 2005; 19(2): 369-375.

[6] Siegler J, Gaskill S, Ruby B. Changes evaluated in soccer-specific power endurance either with or without a 10-week, in season, intermittent, high-intensity training protocol. J Strength Cond Res 2003; 17(2): 379-387.
[7] Nicholas C, Nuttal, F, Williams C. The Loughborough intermittent shuttle. Test: A field test that simulates the activity pattern of soccer. J Sports Sci 2000; 18 (2): 97-104.

[8] Ramsbottom R, Brewer J, Williams, C. A progressive shuttle run test to estimate maximal oxygen uptake. Br J Sports Med 1998; 22 (4): 141-144.

[9] Hamilton A, Nevill M, Brooks S et al. Physiological responses to maximal intermittent exercise. Differences between endurancetrained runners and games players. J Sports Sci 1991; 9(4): 371382.

[10] Wisloff U, Helgerud J, Hoff J. Strength and endurance of elite soccer players. Med Sci Sports Exerc 1998; 30(3): 462-467.

[11] Hickson R, Rosenkoetter M, Brown M. Strength training effects on aerobic power and short-term endurance. Med Sci Sports Exerc 1980; 12(5): 336-339.

[12] Delecluse C. Influence of Strength training on sprint running performance: current findings and implications for training. Sports Med 1997; 24(3): 147-156.

[13] Rimmer E, Sleivert G. Effects of a plyometrics program on sprint performance. J Strength Condit Res 2003; 14(3): 295-301.

[14] Baker, D. Improving vertical jump performance through general, special and specific strength training. J Strength Cond Res 1996; 10(2): 131-136.

[15] Fatoyros I, Jamourtas A, Leontisini D, et al. Evaluation of plyometric exercise training, weight training, and their combination on vertical jumping performance and leg strength. J Strength Cond Res 2000; 14(4): 470-476.

[16] McBride J, Triplett-McBride T, Davie A et al. The effect of heavy vs light -load jump squat on the development of strength, power, and speed. J Strength Cond Res 2002; 16(1): 75-82.

[17] Maffiuletti N, Dugnani S, Folz M et al. The effect of electroestimulation training and basketball practice on muscle strength and jumping ability. Int J Sports Med 2002; 21(6): 437-443.

[18] Bobbert M, Van Soest A. Effect of muscle strengthening on vertical jump height: A simulation study. Med Sci Sports Exerc 1994; 26(8): 1012-1020.

[19] Allen M, Hakkinnen K, Komi P. Changes in neuromuscular performance and muscle activation level and muscle fibre characteristics of elite power players self-administrating androgenic and anabolic steroids. Acta Physiol Scand 1984; 122(4): 535-544.

[20] Hofman J, Kraemer W, Deshenes M et al. The effect of selection for frequency of training in a winter conditioning program for football. J Appl Sport Sci Res 1990; 4(3): 76-82.

[21] Duthie G, Young W, Aitken D. The acute effects of heavy loads on jump squat performance: An evaluation of the complex and contrast methods of power development. J Strength Cond Res 2002; 16(4) 530-538.

[22] Jensen L, Ebben P. Kinetic analysis of complex training rest interval effect on vertical jump performance. J Strength Cond Res 2003;17(2): 345-349.

[23] Toji H, Suei K, Kaneko M. Effects of combined training loads on relations among force, velocity and power training. Appl Physiol Nutr Metab 1997; 22(4): 328-336

[24] Balciunas M, Stonkus S, Abrantes C et al. Long term effects of different training modalities on power, speed, skill and anaerobic capacity in young male basketball players. J Sports Sci Med 2006; 5(1) 163-170.

[25] Bosco C, Luhtanen P, Komi P. A simple method for measurement of mechanical power in jumping. Eur J Appl Physiol 1983; 50(2): 273-82.

[26] Delecluse C, Coppenolle H, Willems E et al. Influence of highresistance and high velocity training on sprint performance. Med Sci Sports Exerc 1995; 27(8): 1203-1209.

[27] Sleivert G, Backus R, Wenger H. The influence of strength-sprint training sequences on multiple join power output. Med Sci Sports Exerc 1995; 27(12): 55-65.

[28] Harris G, Stone M, O'Bryant H et al. Short term performance effects of high speed, high force or combined weight training. J Strength Cond Res 2000; 14(1): 14-20.

[29] Fitzsimons M, Dawson B, Ward D et al. Cycling and running tests of repeated sprint ability. Aust J Sci Med Sports 1993; 25(4) 82-87.

[30] Dowson B, Fitzsimons M, Ward D. The relationship of repeated sprint ability to aerobic power and performance measures of aerobic work capacity and power. Aust J Sci Med Sports 1993; 25(4) 88-93. 
[31] Wragg C, Maxwell N, Dout J. Evaluation of the reliability and validity of a soccer-specific field test of repeated sprint ability. Eur J Appl Physiol 2000; 83(1) 77-83.

[32] Psotta R, Blahus P, Cochrane D et al. The assessment of an intermittent high intensity running test. J Sports Med Phys Fitness 2005; 45(3): 248-256.

[33] Aziz A, Chia M, Teh K. The relationship between maximal oxygen uptake and repeated sprint performance indices in field hockey and soccer players. J Sports Med Phys Fitness 2000; 40(3): 195-200.
[34] Bell G, Syndmiller G, Davis D et al. Relationship between aerobic fitness and metabolic recovery from intermittent exercise in endurance trained players. Can J Appl Physiol 1997; 22(1): 78-85.

[35] Elliot B, Dawson B, Pyke F. The energetics of single tennis. J Hum Mov Stud 1985; 11: 11-20.

[36] Glaister M. Multiple sprint work. Sports Med 2005; 35(9): 757 777.

[37] Mayhew S, Wenger H. Time motion analysis of professional soccer. J Hum Mov Stud 1985; 11: 49-52.

[38] Cohen J, Statistical power analysis for the behavioral sciences. 1988. (2nd ed.). Hillsdale, NJ: Lawrence Earlbaum Associates.

(c) Aguiar et al.; Licensee Bentham Open.

This is an open access article distributed under the terms of the Creative Commons Attribution License (http://creativecommons.org/licenses/by/2.5/), which permits unrestrictive use, distribution, and reproduction in any medium, provided the original work is properly cited. 